\title{
Symptom Relief Following a Single Dose of Propylene Glycol-Hydroxypropyl Guar Nanoemulsion in Patients with Dry Eye Disease: A Phase IV, Multicenter Trial
}

This article was published in the following Dove Press journal:

Clinical Ophthalmology

\author{
Steven Silverstein (1D) \\ Elizabeth Yeu $\mathbb{D}^{2}$ \\ Joseph Tauber (1D) ${ }^{3}$ \\ Michel Guillon (D) ${ }^{4}$ \\ Lyndon Jones $\mathbb{D}^{5,6}$ \\ David Galarreta $\mathbb{1 D}^{7}$ \\ Sruthi Srinivasan (1D ${ }^{8}$ \\ Venkiteshwar Manoj ${ }^{8}$ \\ 'Silverstein Eye Centers, Kansas City, \\ MO 64133, USA; ${ }^{2}$ Virginia Eye \\ Consultants, Norfolk, VA 23502, USA; \\ ${ }^{3}$ Tauber Eye Center, Kansas City, MO \\ 64I55, USA; ${ }^{4}$ Ocular Technology Group \\ International, London SWIE 6AU, UK; \\ ${ }^{5}$ Centre for Ocular Research \& Education \\ (CORE), School of Optometry and Vision \\ Science, Waterloo, ON NL2 3G I, \\ Canada; ${ }^{6}$ Centre for Eye and Vision \\ Research Limited (CEVR), Hong Kong; \\ ${ }^{7}$ Hospital Clinico Universitario de \\ Valladolid, Valladolid Castilla y Leon \\ 470II, Spain; ${ }^{8}$ Alcon Research, LLC, \\ Johns Creek, GA, USA
}

Purpose: To evaluate symptom relief in patients with dry eye disease (DED) following a single drop of propylene glycol-hydroxypropyl guar (PG-HPG) nanoemulsion (Systane ${ }^{\circledR}$ Complete) lubricant eye drops.

Methods: This was a Phase IV, multicenter, open-label, interventional study in adult patients with DED of aqueous-deficient, evaporative, and mixed subtypes. Patients instilled one drop of PG-HPG in each eye at Day 1. Endpoints included change from baseline in dry eye symptom and soothing sensation scores on Day 1 at 0,4 , and 8 hours post-dose. Symptom scores were assessed on a $0-10$ scale ( $0=$ no symptoms; $10=$ worst imaginable symptom). Tolerability of the drop was assessed based on assessment score on Day 1 following instillation for overall cohort and by DED subtype.

Results: A total of 134 patients received treatment (mean age: 56.6 years; female: $75.4 \%$ ). Median changes from baseline at Day 1 in dry eye symptom scores were $-1.0(95 \%$ confidence interval [CI]:-3.0,-1.0), -2.0 (95\% CI:-3.0,-2.0), and -2.0 (95\% CI:-2.0,-1.0) at 0,4 , and 8 hours respectively. Subgroup analysis showed a median change from baseline in dry eye symptom score of -2 (95\% CI:-3.0,-1.0) for aqueous-deficient and evaporative subtypes and -1 (95\% CI:-3.0,-1.0) for mixed subtype at 8 hours. Median soothing sensation scores were 3 at 0 and 4 hours and 3.5 at 8 hours, with a range of $0-10$. Median (range) tolerability assessment scores were $0(0-8)$ for burning sensation, stinging sensation, blurring, and $0(0-10)$ for foreign body sensation. Tolerability assessment scores by DED subtype confirmed that the majority of patients reported scores in the range of $0-5$ for all components and in all subgroups analyzed.

Conclusion: Our study demonstrated that PG-HPG nanoemulsion provided instant/immediate and sustained symptom relief for 8 hours post-single application and was well tolerated in patients with DED, demonstrated by their responses on each of the assessment scales.

Keywords: aqueous-deficient dry eye, dry eye disease, evaporative dry eye, propylene glycol-hydroxypropyl guar nanoemulsion ocular lubricant, mixed dry eye

\section{Introduction}

Dry eye disease (DED), a multifactorial disease of the ocular surface, is one of the most common reasons for frequent patient visits to eye care practitioners, affecting an estimated 30 million people in the US. ${ }^{1,2}$ The global prevalence of DED reported in several large studies ranges from $5 \%$ to $50 \%$, with meibomian gland dysfunction (MGD) reported in about $70 \%$ of dry eye cases. ${ }^{3}$ The symptoms and visual
Silverstein Eye Centers, Kansas City, MO 64133, USA

Tel + I 816.358.3600

$\mathrm{Fax}+1816.358 .1887$

Email ssilverstein@silversteineyecenters. com 
disturbances associated with DED have a negative impact on the daily routine and social or quality of life of patients. Therefore, relief from the symptoms of dryness is critical. ${ }^{4}$ The treatment goal for DED patients is to improve their ocular comfort by restoring their ocular surface and tear film to the normal state.

The Tear Film and Ocular Surface Society (TFOS) published the second Dry Eye Workshop (DEWS II) findings, which emphasize that the tear film should be broadly considered a two-layered structure, with a lipid layer overlying a muco-aqueous phase. ${ }^{5}$ It is likely that interactions of the entire tear film, including lipids, mucins, proteins, and salts, maintain tear film homeostasis, and thus a lubricant that addresses all layers of the tear film is needed. The use of artificial tear products (ATPs), which attempt to replace and/or supplement the deficient natural tear film, remains the primary treatment option in the management of DED. ${ }^{4}$ However, most ATPs are designed to replenish either the lipid or aqueous layer of the tear film. ${ }^{4}$

PG-HPG nanoemulsion (Systane ${ }^{\circledR}$ Complete [Alcon, Inc., Fort Worth, TX, USA]) lubricant eye drops utilize propylene glycol as the active demulcent with a higher amount of hydroxypropyl guar (HPG) gelling technology than the previous Systane ${ }^{\circledR}$ Balance formulation plus a lipid excipient in smaller nano-sized droplets to optimize the lipid surface coverage with a more translucent appearance. ${ }^{6}$ It is intended for patients with dry eye due to either lipid or aqueous deficiency. The unique formulation also contains excipients which can be used in patients with mixed DED. Following application of PG-HPG nanoemulsion, the HPG/ borate meshwork is activated, forming a protective viscoelastic barrier on the surface epithelium. As $\mathrm{pH}$ equilibrates and sorbitol is diluted, the viscoelastic HPG meshwork continues to cross-link, maintaining the protective barrier while acting as a depot for slow release of lipid into the tear film. ${ }^{5}$ The anionic phospholipid DMPG (dimyristoyl phosphatidylglycerol) migrates toward the top of the tear film where it fuses with the existing lipids to supplement and stabilize any gaps that have developed due to lipid insufficiency which is caused by MGD. This nanoemulsion formulation restores the complete tear structure to prevent exacerbations of dry eye and maintain a healthier ocular surface. ${ }^{7-10}$ This study will help us understand the short-term use of PG-HPG nanoemulsion. The purpose of this study was to evaluate the potential rapid improvement in symptom relief in patients with all types of DED following a single drop of propylene glycolhydroxypropyl guar (PG-HPG) nanoemulsion.

\section{Methods}

\section{Study Design}

This was a Phase IV, multicenter, open-label, singlearm, interventional study in adult patients with DED of all major subtypes (aqueous-deficient, evaporative, and mixed) and was registered on a clinical trials database (NCT03492541). Patients were evaluated on four occasions: Screening Visit (Day -7 to Day 0), Visit 1/baseline Visit (Day 1), Visit 2 (Day 14), and Visit 3 (Day 28).

\section{Key Eligibility Criteria}

The study population consisted of adult male and female patients with a clinical diagnosis of DED or dry eye associated with MGD. Key inclusion and exclusion criteria of this study have been previously discussed ${ }^{10}$ and are also shown in Table 1.

\section{Objectives and Endpoints}

The focus of this analysis is to evaluate the improvement in dry eye symptom relief, soothing sensation, and the tolerability drop profile following a single dose of PG-HPG nanoemulsion on Day 1 in patients with DED. Instant and sustained relief of dry eye symptoms over an 8-hour period was assessed. Symptom relief was assessed based on the change from baseline in dry eye symptom and soothing sensation scores on Day 1 at three time points $(0,4$, and 8 hours post-dose). The tolerability drop profile was assessed based on the assessment score on Day 1 following instillation.

\section{Assessments}

A single drop was administered in the morning, and patients were asked not to administer any further drops for 8 hours. Dry eye symptoms and soothing sensation were recorded for patient-reported outcome (PRO) assessment using a Likert scale at baseline (pre-dose) and 0 hours (ie, immediately after dosing) in patients and at $4( \pm 1)$ and $8( \pm 1)$ hours post-dose on the telephone on the same day. A PRO assessment questionnaire was used to evaluate the tolerability profile (ie, burning, stinging, blur, and foreign body sensation) following the instillation of a single drop at the baseline visit. The assessment was undertaken at baseline (prior to eye drop use) and post-eye drop instillation at T-0 hours immediately upon instillation, T-4 $( \pm 1)$ hours, and T-8 $( \pm 1)$ hours. A 10-point analog scale was used to record 
Table I Key Eligibility Criteria

\begin{tabular}{|c|c|}
\hline Key Inclusion Criteria & Key Exclusion Criteria \\
\hline $\begin{array}{l}\text { I. Had a TFBUT of } \leq 5 \text { seconds } \\
\text { in at least one eye at } \\
\text { Screening Visit. } \\
\text { 2. Exhibited symptoms of dry } \\
\text { eye at the Screening Visit } \\
\text { (IDEEL symptom bother } \\
\text { score of }>16 \text { to } 65 \text { ). } \\
\text { 3. Met at least one of the } 3 \\
\text { criteria below in at least } \\
\text { one eye at the Screening } \\
\text { Visit (randomization strati- } \\
\text { fied based on the criteria } \\
\text { below): } \\
\text { (a) Unanesthetized Schirmer } \\
\text { I test score of } \leq 9 \text { mm } \\
\text { (aqueous-deficient dry eye } \\
\text { stratum). } \\
\text { (b) Had a meibum quality } \\
\text { score of } \geq \text { I (on a } 0 \text { to } 3 \\
\text { scale) or meibum expres- } \\
\text { sibility score of }>\text { I (on a } 0 \\
\text { to } 3 \text { scale) in either eye lid } \\
\text { (evaporative dry eye } \\
\text { stratum). } \\
\text { (c) Patients who met both } \\
\text { entry criteria (a) and (b) } \\
\text { (mixed dry eye stratum). } \\
\text { 4. Had best corrected visual } \\
\text { acuity (BCVA) of } \geq 20 / 80 \\
\text { (or } \geq 55 \text { letters score or } \\
\geq 0.6 \text { Early Treatment } \\
\text { Diabetic Retinopathy Study } \\
\text { log of the minimum angle of } \\
\text { eyes at the Screening Visit). }\end{array}$ & $\begin{array}{l}\text { 1. History of hypersensitivity to } \\
\text { the study drug or any of its } \\
\text { excipients or to drugs of simi- } \\
\text { lar chemical classes } \\
\text { 2. History of malignancy of any } \\
\text { organ system (other than } \\
\text { localized basal cell carcinoma } \\
\text { of the skin or in situ cervical } \\
\text { cancer), treated or untreated, } \\
\text { within the past } 5 \text { years, } \\
\text { regardless of whether there } \\
\text { was evidence of local recur- } \\
\text { rence or metastases } \\
\text { 3. Use of any topical ocular med- } \\
\text { ication preserved with ben- } \\
\text { zalkonium chloride or other } \\
\text { products known to be toxic to } \\
\text { the tear film lipid layer within } \\
\text { I month prior to the } \\
\text { Screening Visit } \\
\text { 4. Lid hygiene therapy initiated } \\
\leq 4 \text { weeks prior to the } \\
\text { Screening Visit } \\
\text { 5. Ocular abnormalities that } \\
\text { could adversely affect the } \\
\text { safety or efficacy outcome } \\
\text { 6. Uncontrolled active systemic } \\
\text { diseases, active ocular } \\
\text { infection } \\
\text { 7. Punctal plug insertion or dia- } \\
\text { thermy procedure initiated } \\
\text { within } 30 \text { days prior to the } \\
\text { Screening Visit }\end{array}$ \\
\hline
\end{tabular}

Abbreviations: IDEEL, impact of dry eye on everyday life; TFBUT, tear film break-up time.

symptoms $(0=$ no symptoms at all, $10=$ worst imaginable symptoms $)$ and soothing sensation $(0=$ eyes feeling good, $10=$ no soothing feeling at all) and to establish the tolerability profile (burning, stinging, foreign body sensation and blur $(0=$ none, $10=$ worst $))$. Categorization of 0-5 represents none to mild discomfort and 6-10 represent greater level of discomfort. ${ }^{11,12}$

\section{Subgroup Analyses}

Subgroup analyses by dry eye subtype (aqueous-deficient, evaporative, and mixed) were also performed.

\section{Statistical Analysis}

\section{Sample Size Calculation}

The overall sample size for the full study, which assessed patients at Days 1, 14, and 28, was calculated based on an estimate of the mean change from baseline on Day 14 with reasonable accuracy (with a $95 \%$ confidence interval [CI]). A randomized study comparing Systane Balance with Refresh Optive Advanced administered four times per day for 35 days in 231 patients found that the mean change from baseline in TFBUT for the Systane ${ }^{\circledR}$ Balance arm at Day 15 was equal to 0.70 seconds (95\% CI: $0.29-1.10){ }^{13}$ Using these results as reference, the expected number of patients needed to estimate the $95 \%$ CI with a precision of 0.38 when the SD was 2.1 was 120 patients. Therefore, including a dropout rate of approximately $10 \%$, a total of 134 patients would need to be enrolled in the study.

Dry eye symptom and soothing sensation scores (results binned into 0-5 and 6-10 scores) were summarized using counts and percentages for three time-points $(0$, 4 , and 8 hours post-dose) following instillation on Day 1 for the overall population and by subtype. Similarly, tolerability assessment scores (burning, stinging, blur, and foreign body sensation scores) were summarized using categories for each score (also binned into $0-5$ and 6-10) following instillation on Day 1 for the overall population and by subtype. Additionally, a 95\% CI using Student's t-distribution was provided for the estimated mean change from baseline at Day 1 . If normality criteria were not met, a 95\% CI for the median using the HodgesLehmann estimator was provided instead. All examinations were reported by dry eye subtype and for the worse eye only, which was determined by tear film break-up time.

\section{Results}

\section{Demographic and Baseline Characteristics}

A total of 183 patients were evaluated for eligibility, 134 (73.2\%) received the treatment, of which 130 (97\%) completed and 4 (3\%) discontinued the study. The main reason for failing screening was not meeting inclusion or exclusion criteria (48 patients, $26.2 \%$ ) and the expected number of patients needed to estimate $95 \%$ CI was 120 . The mean (SD) age of patients was $56.6(14.78)$ years, and majority of the patients were female (75.4\%). A similar number of patients were identified for each of the dry eye subtypes: 
Table 2 Demographic and Baseline Characteristics (Full Analysis Set)

\begin{tabular}{|c|c|}
\hline Characteristics & PG-HPG N=134 \\
\hline Mean (SD) age, $n(\%)$ years & $56.6(14.78)$ \\
\hline \multicolumn{2}{|l|}{ Age, n (\%) } \\
\hline$\leq 65$ years & $88(65.7)$ \\
\hline$\geq 65$ years & $46(34.3)$ \\
\hline Female, n (\%) & I0I (75.4) \\
\hline \multicolumn{2}{|l|}{ Race, n (\%) } \\
\hline White & $100(74.6)$ \\
\hline Black or African American & $23(17.2)$ \\
\hline Asian & $6(4.5)$ \\
\hline Other & $4(3.0)$ \\
\hline Multiracial & $\mathrm{I}(0.7)$ \\
\hline \multicolumn{2}{|l|}{ Dry eye subtype, n (\%) } \\
\hline Aqueous-deficient & $4 \mathrm{I}(30.6)$ \\
\hline Evaporative & $44(32.8)$ \\
\hline Mixed & $49(36.6)$ \\
\hline \multicolumn{2}{|l|}{ Dry eye symptom score, n (\%) } \\
\hline $0-5$ & $72(53.7)$ \\
\hline $6-10$ & $61(45.5)$ \\
\hline Missing & I (0.7) \\
\hline
\end{tabular}

Notes: All baseline characteristics were assessed before instillation. Percentages are based on the number of patients in the full analysis set. Full analysis set consisted of all patients who received at least one drop of PG-HPG lubricant eye drops.

Abbreviations: PG-HPG, propylene glycol-hydroxypropyl guar lubricant eye drops; SD, standard deviation.

aqueous-deficient, 41 (30.6\%); evaporative, 44 (32.8\%); and mixed, 49 (36.6\%) (Table 2).

\section{Outcomes}

\section{Dry Eye Symptom Scores}

Dry eye symptom score data improved over time for the symptoms reported by patients after instillation of eye drops on Day 1. The median reduction in symptom scores was $>1$ point at all post-dose time-points for all the patients. Change from baseline in dry eye symptom score on Day 1 for the overall population is shown in Figure 1A. Of 61 patients with the baseline score of 6-10, $41(67.2 \%), 47$ (77.0\%) and $43(70.5 \%)$ patients reported a score of $0-5$ at 0 (immediately after instillation), 4 and 8 hours post-baseline, respectively. The median change from baseline at Day 1 in dry eye symptom score reported by all patients was -1.0 (95\% CI: $-3.0,-1.0)$ at 0 hours, $-2.0(95 \% \mathrm{CI}:-3.0,-2.0)$ at 4 hours, and $-2.0(95 \% \mathrm{CI}:-2.0,-1.0)$ at 8 hours.

The median symptom score reported by aqueousdeficient dry eye patients was $-1(95 \% \mathrm{CI}:-3.0,-1.0)$ at
0 hours, $-2.5(95 \% \mathrm{CI}:-4.0,-2.0)$ at 4 hours, and -2 (95\% CI: $-3.0,-1.0)$ at 8 hours, and this was also reported at all three post-baseline time-points in the evaporative dry eye subtype $(-2[95 \% \mathrm{CI}:-3.0,-1.0])$. In the mixed dry eye subtype, the median symptom score reported was -1 (95\% CI: $-3.0,-1.0)$ at 0 hours, -2 (95\% CI: $-3.0,-1.0)$ at 4 hours, and $-1(95 \% \mathrm{CI}:-3.0,-1.0)$ at 8 hours. Change from baseline in dry eye symptom scores on Day 1 by subtype is depicted in Figure 1B.

\section{Soothing Sensation Scores}

The proportion of patients in each category of the soothing sensation score was similar when assessed at all three time-points after the instillation. More than $80 \%$ of patients had a soothing sensation which persisted throughout the 8-hour evaluation period (Figure 2A). The median soothing sensation score was 3 at 0 hours, 3 at 4 hours, and 3.5 at 8 hours (range, $0-10$ ). A subgroup analysis of the soothing sensation score on Day 1 by dry eye subtype confirmed that the majority of patients reported a score of $0-5$ at all time-points after instillation (Figure 2B).

The median (range) symptom score reported by aqueous-deficient dry eye patients was $3.0(0-9)$ at 0 hours, $2.0(0-8)$ at 4 hours, and $3.0(0-8)$ at 8 hours, while the median (range) symptom score reported by evaporative dry eye subtype patients was $3.0(0-10)$ at 0 hours, 3.0 $(0-10)$ at 4 hours, and $4.0(0-9)$ at 8 hours. In the mixed subtype, the median (range) symptom score reported by patients was $3.0(0-10)$ at 0,4 , and 8 hours.

A comparison of the shift from baseline at subsequent time-points, on Day 1, showed an improvement over time in dry eye symptom scores (Table 3 ) and soothing sensation scores (Table 4) in all dry eye subgroups.

\section{Tolerability Assessment Score}

The tolerability assessment questionnaire was administered at the baseline visit (Day 1) immediately after instillation. More than $92 \%$ of patients reported a tolerability assessment score of $0-5$ for each component (burning sensation, stinging sensation, blur, and foreign body sensation). The median tolerability assessment scores were 0 for burning, stinging, and blur (ranges, 0-8), and for foreign body sensation (range, 0-10) (Figure 3A). Subgroup analysis of the tolerability assessment scores by dry eye subtype on Day 1 confirmed that most patients reported scores of $0-5$ for each component after instillation and in all analyzed subgroups (Figure 3B). 
A

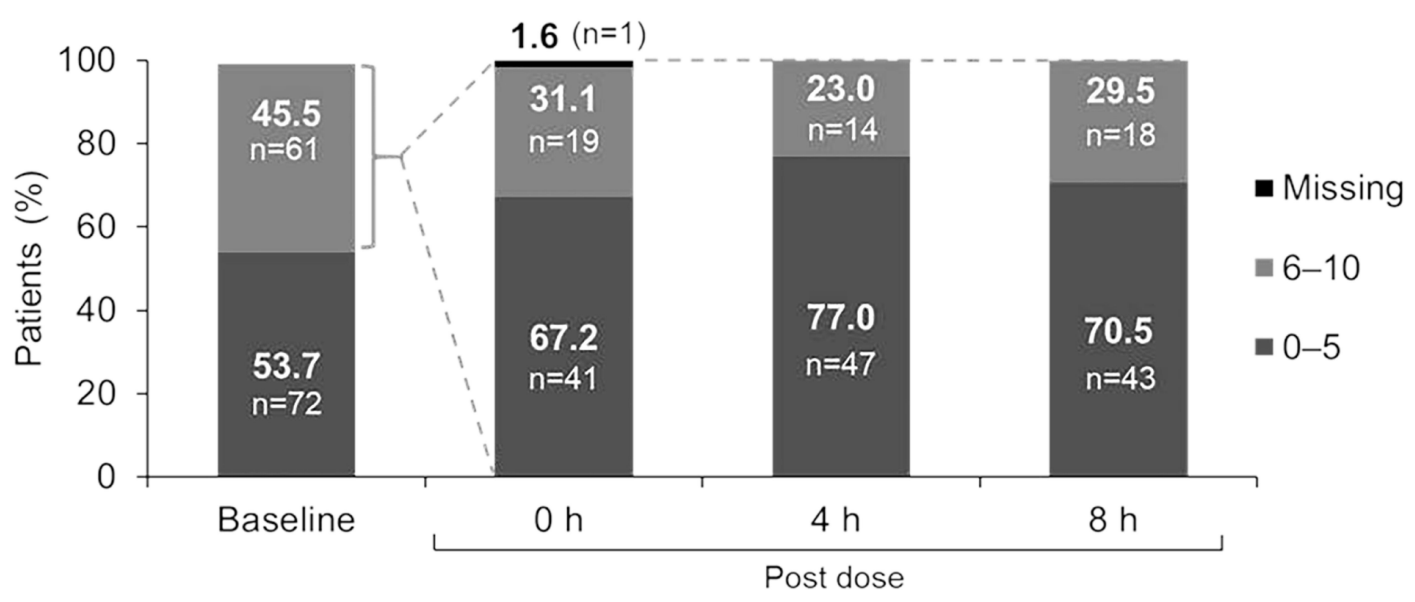

B

Aqueous-deficient $(n=41)$

Evaporative $(n=44)$

ㅂ. $0-5=6-10$

B

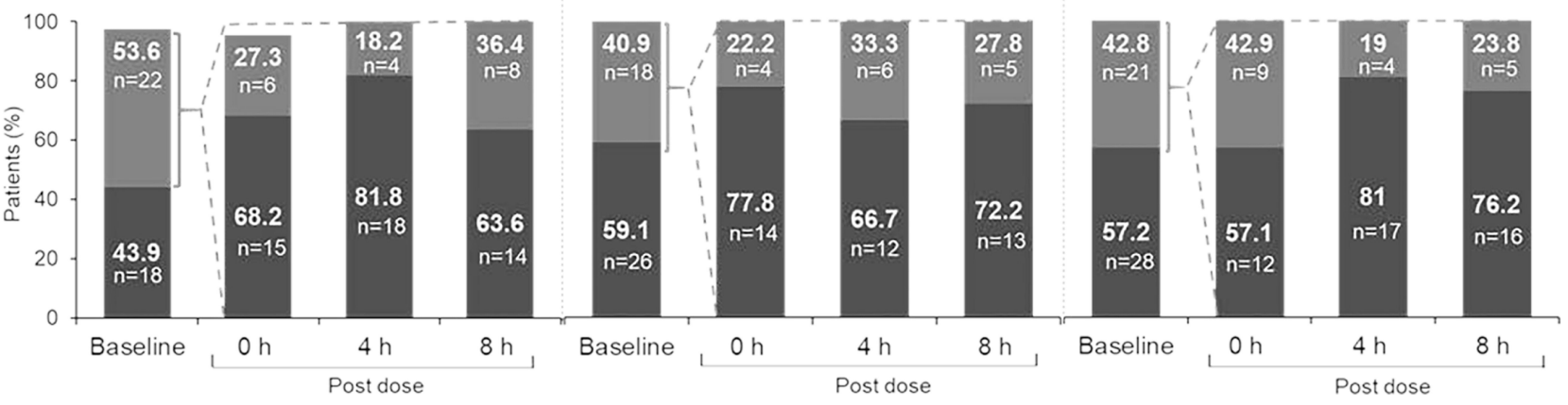

Figure I (A) Change from baseline in dry eye symptom scores on Day I (Overall population, $\mathrm{N}=134$ ). Baseline data for one patient was missing. The change from baseline in median $(95 \% \mathrm{Cl})$ dry eye symptom scores at $0 \mathrm{~h}, 4 \mathrm{~h}$, and $8 \mathrm{~h}$ post-dose were $-\mathrm{I}(-3,-\mathrm{l}),-2(-3,-2)$, and $-2(-2,-1)$, respectively. Patient-reported outcome assessment of dry eye symptoms was performed using $0-10$ visual analog scale at 4 time points on Day I (baseline, 0 (immediate), 4 ( $\pm \mathrm{I}$ ), and 8 ( $\pm \mathrm{I}$ ) hours post-drop instillation; $0-5=$ none to minimal symptoms; $6-10=$ moderate to severe symptoms). Baseline was defined as the last available, non-missing, scheduled or unscheduled value collected prior to exposure to study treatment. (B) Change from baseline in dry eye symptom scores on Day I (by subtype). Baseline and $0 \mathrm{~h}$ data for one patient each in aqueous deficient group was missing. Median reduction in symptom score was $>1$ point at all post-dose time points for all the subtypes. Patient-reported outcome assessment of dry eye symptoms was performed using 0 (no symptoms/eyes feeling good) -10 (worst symptoms/no feeling at all) visual analog scale at 4 time points on Day I (baseline, 0 (immediate), $4( \pm \mathrm{I})$, and $8( \pm \mathrm{I}) \mathrm{h}$ post-drop instillation; $0-5=$ none to minimal symptoms; $6-10=$ moderate to severe symptoms). Baseline was defined as the last available, non-missing, scheduled or unscheduled value collected prior to exposure to study treatment.

Abbreviations: $\mathrm{Cl}$, confidence interval; h, hour; $\mathrm{n}$, number of patients.

In the aqueous-deficient subtype, the median tolerability assessment scores reported by patients were 0 for burning (range, 0-6), stinging (range 0-7), blur (range $0-8$ ), and foreign body sensation (range, $0-5$ ). Median tolerability scores reported by patients with the evaporative subtype were 0 for burning, stinging, and foreign body sensation (ranges 0-8) and for blur (range, 0-7). Similar results were observed for the mixed subtype.

\section{Discussion}

The results of this study demonstrated that the PG-HPG nanoemulsion consistently reduced the symptoms associated with DED in all patients, regardless of the disease subtype, thereby providing the instant, immediate, and allday symptom relief. Immediately following instillation, there was a decrease in dry eye symptom severity that remained lowered throughout the 8-hour follow-up period. The majority of patients reported a soothing sensation immediately post-instillation, with the effect being maintained over the 8-hour follow-up period. This indicates that PG-HPG nanoemulsion provides instant and all-day soothing sensation in dry eye and all its subtypes. The PGHPG nanoemulsion was well tolerated during the study period. Subgroup analysis based upon the subtype of DED showed results which were comparable to that of the overall study cohort. The PG-HPG nanoemulsion provided 


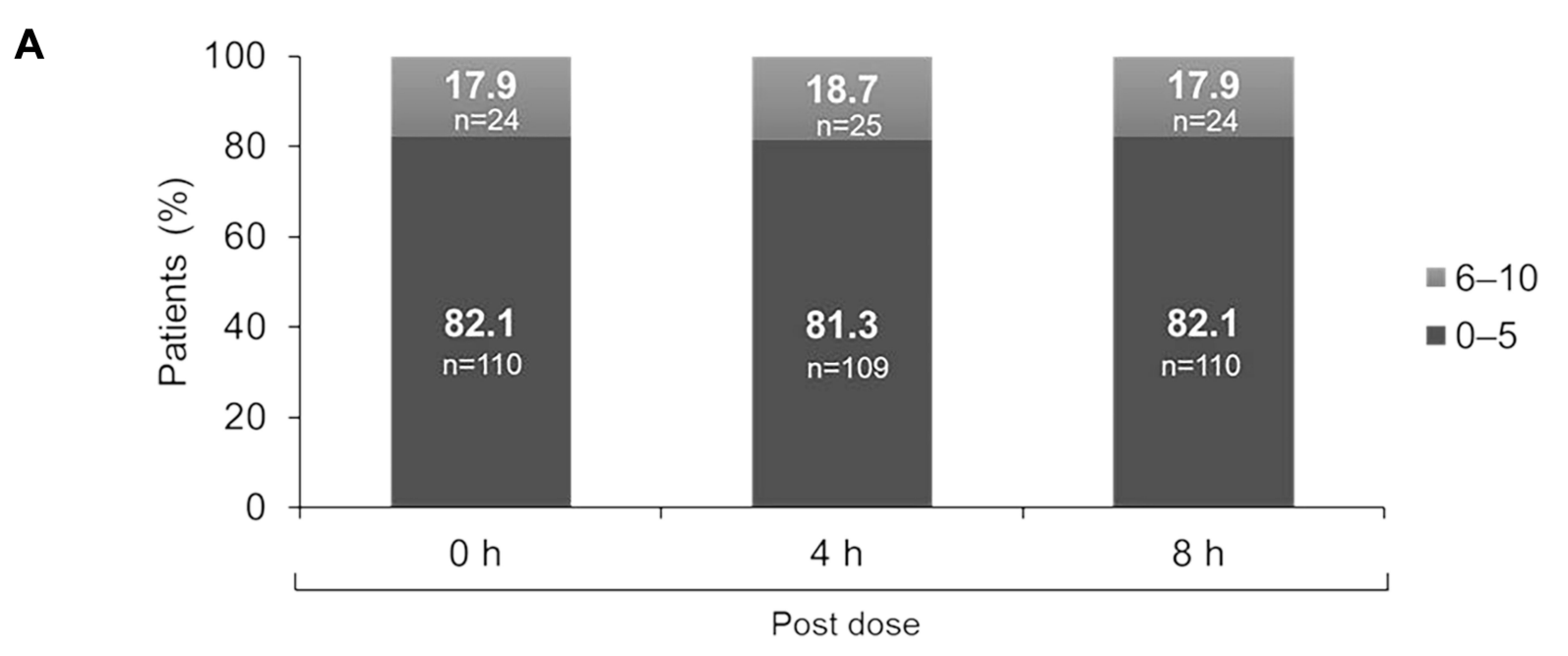

B

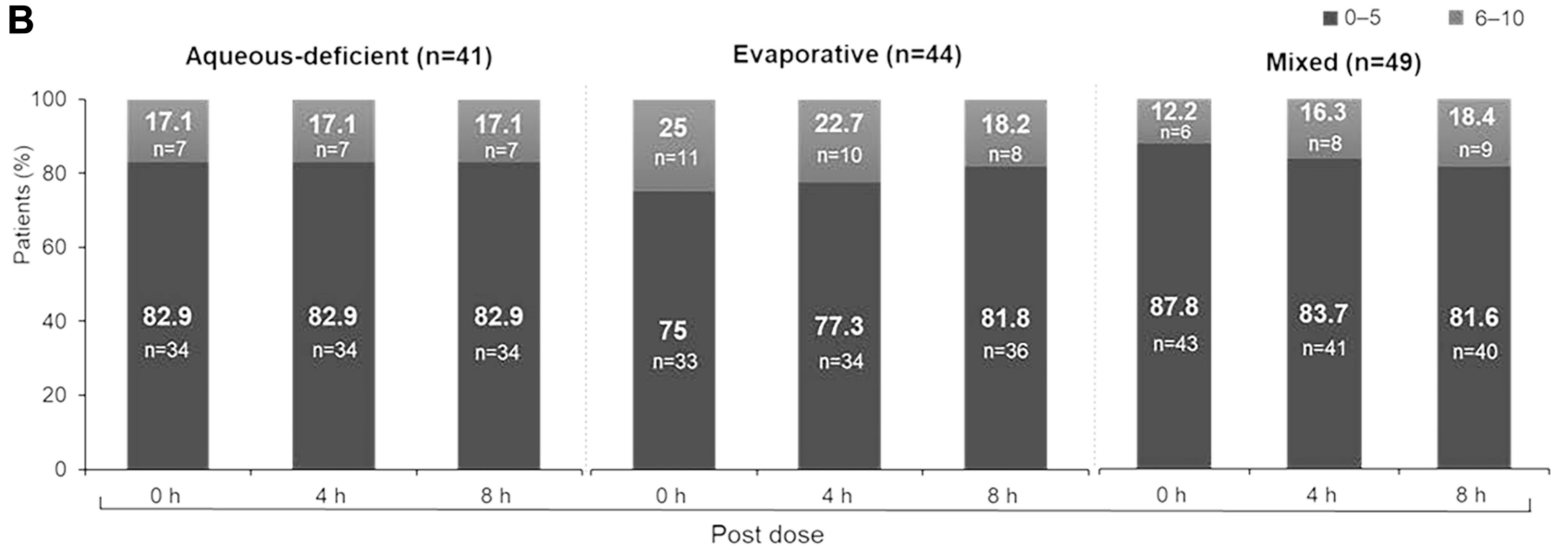

Figure 2 (A) Soothing sensation scores on Day I (Overall population, $\mathrm{N}=134$ ). The median (range) soothing sensation scores at 0,4 , and $8 \mathrm{~h}$ post-dose were 3 ( $0-10$ ), 3.0 $(0-10)$, and $3.5(0-10)$, respectively. Patient-reported outcome assessment of soothing sensation was performed using 0 (no symptoms/eyes feeling good) - 10 (worst symptoms/no feeling at all) visual analog scale at 4 time points on Day I (baseline, 0 (immediate), 4 ( $\pm \mathrm{I}$ ), and 8 ( $\pm \mathrm{I}$ ) h post-drop instillation; $0-5=$ none to minimal symptoms; 6-10 = moderate to severe symptoms). (B) Soothing sensation scores on Day I (by subtype). Patient-reported outcome assessment of soothing sensation was performed using 0 (no symptoms/eyes feeling good) - 10 (worst symptoms/no feeling at all) visual analog scale at 4 time points on Day I (baseline, 0 (immediate), 4 ( \pm I), and $8( \pm I)$ h post-drop instillation; $0-5=$ none to minimal symptoms; $6-10=$ moderate to severe symptoms).

Abbreviations: $h$, hours; $N$, total number of patients.

8-hour relief of dry eye symptoms following a single eye drop instillation, regardless of the dry eye subtype. ${ }^{14}$ This PG-HPG nanoemulsion is the first Systane ${ }^{\circledR}$ product that combines the previously reported benefits of $\mathrm{HPG}^{8,9}$ in a nanoparticle formulation technology (that has a reduced lipid droplet size $<100 \mathrm{~nm}$ ), and represents an evolution of Systane ${ }^{\circledR}$ Balance, which was designed as a lipid replenishment ATP. Similar to Systane ${ }^{\circledR}$ Balance, this PG-HPG nanoemulsion contains an anionic phospholipid and mineral oils for lipid layer functionality and is effective against evaporative dry eye. ${ }^{15}$ This formulation utilizes the same active demulcent as Systane ${ }^{\circledR}$ Balance, ie, propylene glycol $(0.6 \%)$, but in combination with three times the amount of HPG gelling technology, and a lipid excipient in smaller nano-sized droplets, enhancing retention on the ocular surface of the lubricant. ${ }^{16}$

The smaller nano-sized lipid droplets also optimize the lipid surface coverage and make the emulsion formulation less opaque (ie, translucent), improving ocular surface coverage and minimizing blurring, helping to provide the instant (at 0 hour) and sustained symptom relief over an 8-hour period. Such a formulation has the potential to restore both aqueous and lipid layer deficiency of the tear film. A tear replacement ATP that is targeted at managing all forms of DED simplifies the selection process for a clinician and may help address a patient's dry 
Table 3 Dry Eye Symptom Score (0-5, 6-10): Shift Table Between Subsequent Time Points on Day I

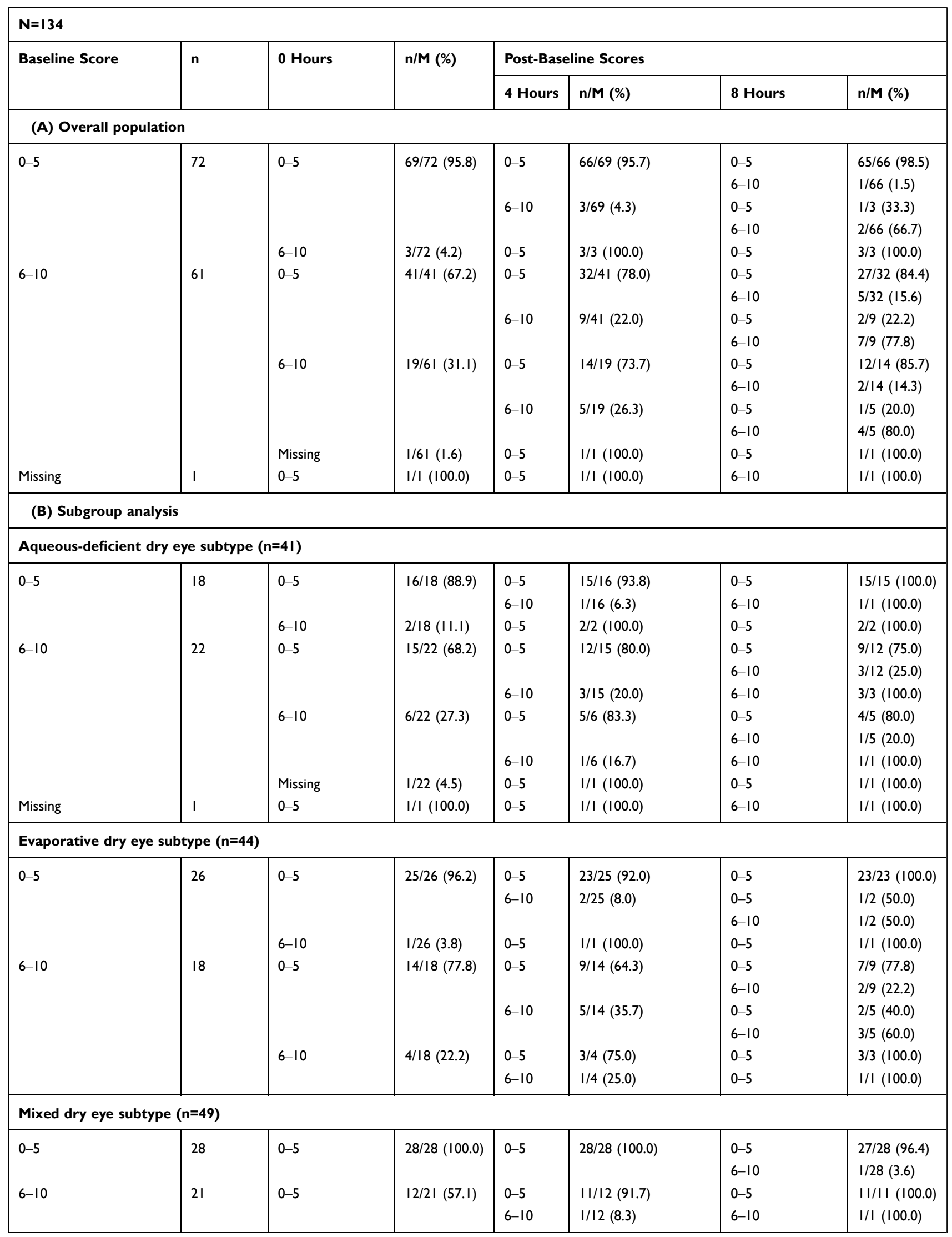

(Continued) 
Table 3 (Continued).

\begin{tabular}{|c|c|c|c|c|c|c|c|}
\hline \multicolumn{8}{|l|}{$N=134$} \\
\hline \multirow[t]{2}{*}{ Baseline Score } & \multirow[t]{2}{*}{$\mathbf{n}$} & \multirow[t]{2}{*}{0 Hours } & \multirow[t]{2}{*}{$n / M(\%)$} & \multicolumn{4}{|c|}{ Post-Baseline Scores } \\
\hline & & & & 4 Hours & $n / M(\%)$ & 8 Hours & n/M (\%) \\
\hline & & $6-10$ & $9 / 21(42.9)$ & $\begin{array}{l}0-5 \\
6-10\end{array}$ & $\begin{array}{l}6 / 9(66.7) \\
3 / 9(33.3)\end{array}$ & $\begin{array}{l}0-5 \\
6-10 \\
6-10\end{array}$ & $\begin{array}{l}5 / 6(83.3) \\
1 / 6(16.7) \\
3 / 3(100.0\end{array}$ \\
\hline
\end{tabular}

Notes: Full analysis set $\mathrm{n}$ is the number of patients on the respective category at the particular time point. $M$ is the number of patients included in the respective category of the previous time point. Percentages are based on M. Baseline dry eye symptom assessment is obtained prior to dosing.

Table 4 Soothing Sensation Score (0-5, 6-10): Shift Table Between Subsequent Time Points on Day I

\begin{tabular}{|c|c|c|c|c|c|}
\hline \multicolumn{6}{|l|}{$N=134$} \\
\hline 0 Hours & $\mathbf{n}$ & 4 Hours & $n / M(\%)$ & 8 Hours & n/M (\%) \\
\hline \multicolumn{6}{|c|}{ (A) Overall population } \\
\hline \multirow[t]{4}{*}{$0-5$} & 110 & $0-5$ & $98 / 110(89.1)$ & $0-5$ & $91 / 98(92.9)$ \\
\hline & & & & $6-10$ & 7/98 (7.1) \\
\hline & & $6-10$ & $12 / 110(10.9)$ & $0-5$ & $6 / 12(50.0)$ \\
\hline & & & & $6-10$ & $6 / 12(50.0)$ \\
\hline \multirow[t]{4}{*}{$6-10$} & 24 & $0-5$ & II/24 (45.8) & $0-5$ & $9 / 11(81.8)$ \\
\hline & & & & $6-10$ & $2 / 11(18.2)$ \\
\hline & & $6-10$ & 13/24 (54.2) & $0-5$ & $4 / 13(30.8)$ \\
\hline & & & & $6-10$ & $9 / 13(69.2)$ \\
\hline \multicolumn{6}{|c|}{ (B) Subgroup analysis } \\
\hline \multicolumn{6}{|c|}{ Aqueous-deficient dry eye subtype $(n=4 I)$} \\
\hline \multirow[t]{3}{*}{$0-5$} & 34 & $0-5$ & $30 / 34(88.2)$ & $0-5$ & $29 / 30(96.7)$ \\
\hline & & & & $6-10$ & $1 / 30(3.3)$ \\
\hline & & $6-10$ & $4 / 34(11.8)$ & $6-10$ & $4 / 4(100.0)$ \\
\hline \multirow[t]{3}{*}{$6-10$} & 7 & $0-5$ & $4 / 7(57.1)$ & $0-5$ & $4 / 4(100.0)$ \\
\hline & & $6-10$ & $3 / 7(42.9)$ & $0-5$ & I/3 (33.3) \\
\hline & & & & $6-10$ & $2 / 3(66.7)$ \\
\hline \multicolumn{6}{|c|}{ Evaporative dry eye subtype $(n=44)$} \\
\hline \multirow[t]{4}{*}{$0-5$} & 33 & $0-5$ & $28 / 33(84.8)$ & $0-5$ & $26 / 28(92.9)$ \\
\hline & & & & $6-10$ & 2/28 (7.1) \\
\hline & & $6-10$ & $5 / 33(15.2)$ & $0-5$ & $3 / 5(60.0)$ \\
\hline & & & & $6-10$ & $2 / 5(40.0)$ \\
\hline \multirow[t]{4}{*}{$6-10$} & 11 & $0-5$ & $6 / 11(54.5)$ & $0-5$ & $5 / 6(83.3)$ \\
\hline & & & & $6-10$ & $1 / 6(16.7)$ \\
\hline & & $6-10$ & $5 / 11(45.5)$ & $0-5$ & $2 / 5(40.0)$ \\
\hline & & & & $6-10$ & $3 / 5(60.0)$ \\
\hline \multicolumn{6}{|c|}{ Mixed dry eye subtype $(n=49)$} \\
\hline \multirow[t]{3}{*}{$0-5$} & 43 & $0-5$ & $40 / 43(93.0)$ & $0-5$ & $36 / 40(90.0)$ \\
\hline & & & & $6-10$ & $4 / 40(10.0)$ \\
\hline & & $6-10$ & $3 / 43(7.0)$ & $0-5$ & $3 / 3(100.0)$ \\
\hline \multirow[t]{3}{*}{$6-10$} & 6 & $0-5$ & $1 / 6(16.7)$ & $0-5$ & $\mathrm{I} / \mathrm{I}(100.0)$ \\
\hline & & $6-10$ & $5 / 6(83.3)$ & $0-5$ & I/5 (20.0) \\
\hline & & & & $6-10$ & $4 / 5(80.0)$ \\
\hline
\end{tabular}

Notes: Full analysis set $\mathrm{n}$ is the number of patients on the respective category at the particular time point. $\mathrm{M}$ is the number of patients included in the respective category of the previous time point. Percentages are based on $\mathrm{M}$. 
A

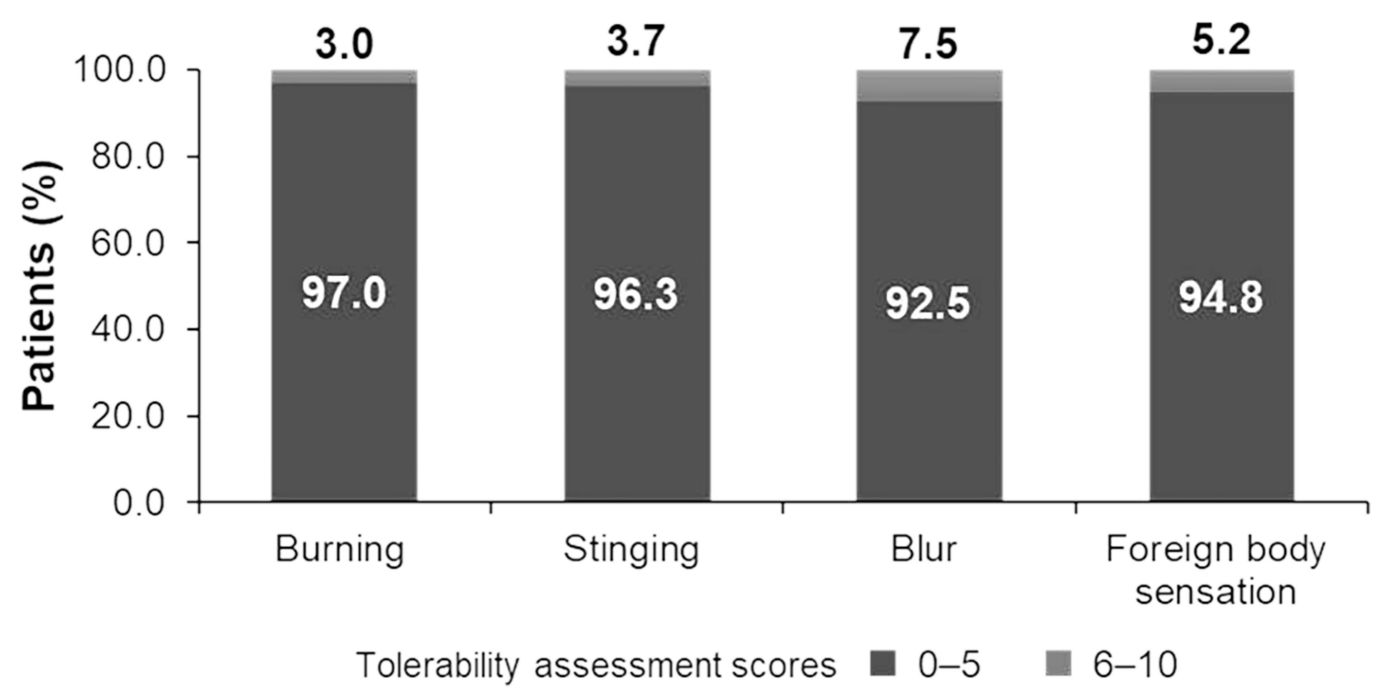

B

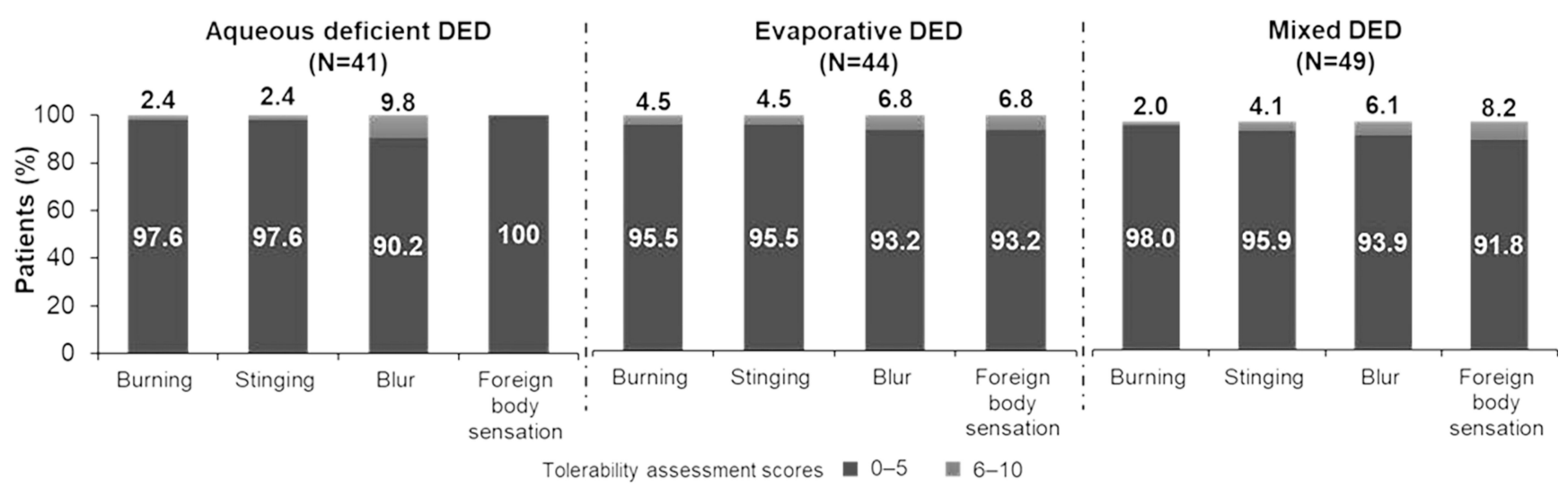

Figure 3 (A) Tolerability assessment score on Day I (Overall population). Tolerability profile was assessed on a 0-10 scale (0=no symptoms; I0=worst imaginable symptom experienced; $0-5=$ none to mild symptoms; $6-10=$ moderate to severe symptoms). (B) Tolerability assessment score on Day I (by subtype). Tolerability profile was assessed on a $0-10$ scale $(0=$ no symptoms; $10=$ worst imaginable symptom experienced; $0-5=$ none to mild symptoms; $6-10=$ moderate to severe symptoms).

eye symptoms regardless of the deficiency within the tear film responsible for their symptoms.

The increased concentration of HPG (compared with Systane $^{\circledR}$ Balance) in this PG-HPG nanoemulsion allows better cross linking with borate ions, improving the retention of the lubricant (PG) within the aqueous/mucin layer and moisture content of the deficient aqueous tear film. ${ }^{14}$ The benefits of a formulation interacting with both layers of the tear film are clinically of great importance, as according to the TFOS DEWS II consensus reports, ${ }^{3,5}$ most patients suffering from the symptoms of dry eye have mixed mechanism disease, requiring management of both the lipid and aqueous mucin layers.

Categorization of analog scale scores as $0-5$ and 6-10 was based on previous studies that used similar categorization methods on a $0-100$ scale. $^{11,12}$ As a part of the original data analysis plan, change in categorization scores $(0-5,6-10)$ was not evaluated as a function of the baseline values. However, the significance is based on the mean change in visual analogue scale scores.

Several previous studies have assessed the effects of instillation of a single eye drop on subjective symptoms of dry eye disease. For example, instillation of a single drop $(40 \mu \mathrm{L})$ of eye drops containing sodium hyaluronate into 13 subjects with dry eye was significantly better at relieving dry eye symptoms for 6 hours than saline. ${ }^{17}$ Similarly, instillation of a single drop of eye drops containing sodium hyaluronate into 50 subjects with dry eye was significantly better than saline at relieving dry eye symptoms for 2 hours. $^{18}$ 
This study had several limitations, including the lack of hypothesis testing. Moreover, the results of this study were based purely on the patients' subjective responses to the questionnaire. Since this study did not include a control group, the reduction in symptom score immediately following drop instillation cannot be differentiated from a placebo effect. However, given that the efficacy data from a similar composition with anionic phospholipid are well established, the increased HPG concentration and nanoemulsion formulation were able to provide 8-hour relief which has not been established with a placebo effect. Clinical studies that include a comparator or control arm should be considered in the future.

\section{Conclusions}

Our study demonstrated that a novel PG-HPG nanoemulsion provided instant/immediate and sustained symptom relief for 8 hours following a single application and was well tolerated by the majority of study patients. Tolerability assessment scores immediately after instillation of a single drop of PG-HPG nanoemulsion lubricant eye drops were $0-5$ for each component in patients with DED, irrespective of DED subtypes.

\section{Data Sharing Statement}

Due to varying rights of individuals and contractual rights of parties involved, Alcon does not make a practice of sharing datasets.

\section{Acknowledgments}

The medical writing support and editorial assistance during the development of the manuscript was provided by Aditya Pramod (Novartis Healthcare Pvt. Ltd., Hyderabad, India). Editorial support post-submission was provided by BelMed, Inc., which was contracted and funded by Alcon.

\section{Funding}

The study was funded by Alcon Research LLC, Fort Worth, Texas, US. This study is registered with ClinicalTrials.gov as NCT03492541.

\section{Disclosure}

Steven Silverstein: Consultant and research for Alcon. Elizabeth Yeu: Consultant for Alcon, Allergan, Avedro, Avellino, Bausch + Lomb, BioTissue/Tissue Tech, Bruder, BVI, CorneaGen, EyePoint Pharm. Expert Opinion for Glaukos, iOptics, J\&J Vision, LENSAR, Kala Pharm., Merck, Mynosys, Novartis, Ocular
Science, Ocular Therapeutix, OcuSoft, Omeros Oyster Point Pharm, Science Based Health, Shire, Sun Pharm, TearLab Corp, Carl Zeiss. Investor in Avellino, CorneaGen, Melt, Modernizing Medicine, Mynosys, Ocular Science, Strathspey Crown. Research for Alcon, Allergan, TopCon, AcuFocus. Clinical investigator for Novartis. Joseph Tauber: Research for Alcon. Michel Guillon: Consultant and Financial Support for Alcon and reports grants from Optometric Technology Group Ltd. Lyndon Jones: Consultant and/or serves on an advisory board for Alcon, CooperVision, J\&J Vision, Novartis and Ophtecs. Research support or lectureship honoraria from Alcon, Allergan, CooperVision, GL Chemtec, iMed Pharma, J\&J Vision, Lubris, Menicon, Nature's Way, Novartis, Ote, PS Therapy, Safilens, Santen, Shire, SightGlass and Visioneering. David Galarreta: Consultant to Alcon, Bausch + Lomb, Novartis, Santen, Shire, Thea, VISUfarma. Research for Alcon, Allergan, Nicox, Novartis, Sifi. Sruthi Srinivasan and Venkiteshwar Manoj: Employees of Alcon. The authors report no other conflicts of interest in this work.

\section{References}

1. Craig JP, Nichols KK, Akpek EK, et al. TFOS DEWS II definition and classification report. Ocul Surf. 2017;15(3):276-283. doi:10.10 16/j.jtos.2017.05.008

2. Friedman NJ. Impact of dry eye disease and treatment on quality of life. Curr Opin Ophthalmol. 2010;21(4):310-316. doi:10.1097/ICU. 0b013e32833a8c15

3. Stapleton F, Alves M, Bunya VY, et al. TFOS DEWS II epidemiology report. Ocul Surf. 2017;15(3):334-365. doi:10.1016/j.jtos.2017.05.003

4. Jones L, Downie LE, Korb D, et al. TFOS DEWS II management and therapy report. Ocul Surf. 2017;15(3):575-628. doi:10.1016/j.jtos.20 17.05 .006

5. Willcox MDP, Argueso P, Georgiev GA, et al. TFOS DEWS II tear film report. Ocul Surf. 2017;15(3):366-403. doi:10.1016/j.jtos.2017.03.006

6. Patra JK, Das G, Fraceto LF, et al. Nano based drug delivery systems: recent developments and future prospects. J Nanobiotechnology. 2018;16(1):71. doi:10.1186/s12951-018-0392-8

7. Benelli U. Systane lubricant eye drops in the management of ocular dryness. Clin Ophthalmol. 2011;5:783-790. doi:10.2147/OPTH.S13 773

8. Rangarajan R, Ketelson H. Preclinical evaluation of a new hydroxypropyl-guar phospholipid nanoemulsion-based artificial tear formulation in models of corneal epithelium. J Ocul Pharmacol Ther. 2019;35(1):32-37. doi:10.1089/jop.2018.0031

9. Korb DR, Greiner JV, Glonek T. The effects of anionic and zwitterionic phospholipids on the tear film lipid layer. Adv Exp Med Biol. 2002;506(Pt A):495-499.

10. Yeu E, Silverstein S, Guillon M, et al. Efficacy and safety of phospholipid nanoemulsion-based ocular lubricant for the management of various subtypes of dry eye disease: a phase IV, multicenter trial. Clinical Ophthalmol. 2020.

11. Tauber J, Karpecki P, Latkany R, et al. Lifitegrast ophthalmic solution $5.0 \%$ versus placebo for treatment of dry eye disease: results of the randomized Phase III OPUS-2 study. Ophthalmology. 2015;122 (12):2423-2431. doi:10.1016/j.ophtha.2015.08.001 
12. Nichols KK, Holland E, Toyos MM, et al. Ocular comfort assessment of lifitegrast ophthalmic solution $5.0 \%$ in OPUS-3, a phase III randomized controlled trial. Clin Ophthalmol. 2018;12:263-270. doi:10. 2147/OPTH.S152841

13. Jerkins G, Greiner V, Tong L, et al. A comparison of efficacy and safety of two lipid-based lubricant eye drops for the management of evaporative dry eye disease. Clin Ophthalmol. 2020;14:1665-1673. doi:10.2147/OPTH.S256351

14. Systane Complete. Available from: https://systane.myalcon.com/eyecare/systane/products/systane-complete/. Accessed December 26, 2019.

15. Aguilar AJ, Marquez MI, Albera PA, Tredicce JL, Berra A. Effects of systane((R)) balance on noninvasive tear film break-up time in patients with lipid-deficient dry eye. Clin Ophthalmol. 2014;8:23 65-2372. doi:10.2147/OPTH.S70623
16. Gifford P, Evans BJ, Morris J. A clinical evaluation of systane. Cont Lens Anterior Eye. 2006;29(1):31-40. doi:10.1016/j.clae.20 05.12 .003

17. Johnson ME, Murphy PJ, Boulton M. Effectiveness of sodium hyaluronate eyedrops in the treatment of dry eye. Graefes Arch Clin Exp Ophthalmol. 2006;244(1):109-112. doi:10.1007/s00417-005-0028-1

18. Lekhanont K, Chuckpaiwong V, Vongthongsri A, Sangiampornpanit T. Effects of sodium hyaluronate on wavefront aberrations in dry eye patients. Optom Vis Sci. 2014;91(1):39-46. doi:10.1097/OPX.000 0000000000101
Clinical Ophthalmology

\section{Publish your work in this journal}

Clinical Ophthalmology is an international, peer-reviewed journal covering all subspecialties within ophthalmology. Key topics include: Optometry; Visual science; Pharmacology and drug therapy in eye diseases; Basic Sciences; Primary and Secondary eye care; Patient Safety and Quality of Care Improvements. This journal is indexed on PubMed

Submit your manuscript here: https://www.dovepress.com/clinical-ophthalmology-journal
Dovepress

Central and CAS, and is the official journal of The Society of Clinical Ophthalmology (SCO). The manuscript management system is completely online and includes a very quick and fair peer-review system, which is all easy to use. Visit http://www.dovepress.com/ testimonials.php to read real quotes from published authors. 